\title{
Recomendações para a atuação dos fisioterapeutas nos distúrbios respiratórios do sono em pacientes sem e com suspeita ou confirmação de COVID-19*
}

\author{
Recommendations for physiotherapy in sleep-breathing disorders in patients with or without \\ suspected or confirmed COVID-19*
}

\author{
PICCIN, Vivien Schmeling파 FRANCO, Aline Marques²; NERBASS, Flávia Baggio³; em \\ nome do Comitê COVID-19 da ASSOBRAFIR.
}

\begin{abstract}
Resumo
A pandemia da COVID-19 desafia o sistema de saúde. A alta transmissibilidade viral e ausência de tratamento específico torna necessária a adoção de estratégias para mitigação do contágio, que se dá pela dispersão de partículas no ar. A apneia do sono é uma condição clínica que demanda o uso de dispositivos de pressão positiva e acessórios (incluindo interface) pelo paciente. A válvula exalatória contida nas interfaces pode contribuir para maior aerossolização desse ar, aumentando a chance de contágio. Além disso, há grande proximidade física entre paciente e profissional de saúde no período de tratamento inicial, acarretando muitas dúvidas para os fisioterapeutas que atuam na área acerca do manuseio dos dispositivos e condutas mais adequadas. Embasado nas melhores evidências científicas disponíveis, este documento objetiva esclarecer e auxiliar o fisioterapeuta a conduzir e orientar seus pacientes durante o período de pandemia da COVID-19.

Palavras-chave: Fisioterapia; Distúrbios Respiratórios do Sono; Apneia do Sono; COVID-19; Pressão Positiva nas Vias Aéreas.

* Revisado por membros do Comitê COVID-19 da ASSOBRAFIR, nomeado por meio do memorando N 003/2020. Esta publicação é uma atualização da Comunicação oficial "Recomendações para a atuação dos fisioterapeutas nos distúrbios respiratórios do sono em pacientes sem e com suspeita ou confirmação de COVID-19", chancelada pelo Comitê COVID-19 da ASSOBRAFIR, originalmente escrita pelos mesmos autores e divulgada em 07/04/2020 no endereço eletrônico https://assobrafir.com.br/covid-19-fisioterapia-respiratoria-nos-disturbios-respiratorios-do-sono/

${ }^{1}$ Laboratório do Sono do Instituto do Coração da Faculdade de Medicina da Universidade de São Paulo (InCor/FMUSP). Email: vspiccin@gmail.com.br. VSP - https://orcid.org/0000-0001-9540-4128

2 Departamento de Neurociências e Ciências do Comportamento da Faculdade de Medicina de Ribeirão Preto, Universidade de São Paulo (FMRP-USP). AMF - https://orcid.org/0000-0002-5999-5028

${ }^{3}$ Laboratório do Sono do Instituto do Coração da Faculdade de Medicina da Universidade de São Paulo (InCor/FMUSP). FBN - https://orcid.org/0000-0002-5135-4285
\end{abstract}




\section{Abstract}

The COVID-19 pandemic challenges the health care system. High viral transmissibility and the absence of a specific treatment leads to the adoption of strategies to mitigate contamination, caused by the dispersion of particles in the air. Sleep apnoea is a clinical condition that requires the use of positive pressure devices and accessories (e.g., face mask) by the patient. The exhalation exit in the mask may contribute to higher aerosol dispersion, increasing the chance of contaminating the people around. Furthermore, patients and health professionals keep close physical contact during the early period of treatment, raising many doubts for physiotherapists who work in this field regarding the handling of devices and use of techniques. Based on the best scientific evidence available, this document aims to assist the physiotherapist with treating and guiding his/her patient during the pandemic.

Keywords: Physiotherapy; Sleep Respiratory Disorders; Sleep Apnea; COVID-19; Positive Airway Pressure.

\section{Objetivo}

Os objetivos do presente posicionamento são: 1) fornecer direcionamentos para o atendimento de Fisioterapia a pacientes sem e com suspeita ou confirmação de COVID-19*, com foco nos cuidados de uso e higienização de equipamentos de pressão positiva e seus acessórios, além do ambiente onde são utilizados; 2) traçar diretrizes para o uso de EPIs pelos profissionais da área e para o atendimento de pacientes.

\section{Contextualização}

A pandemia da COVID-19 desafia o sistema de saúde mundial. Sua alta transmissibilidade e ausência de tratamento específico tornam necessária a adoção de estratégias para mitigação do contágio nos âmbitos sociais e de assistência à saúde.

A pressão positiva na via aérea superior (PAP, do inglês Positive Airway Pressure) é o tratamento principal e mais eficaz para a apneia obstrutiva do sono (AOS) moderada a grave. Esse suporte ventilatório não invasivo aumenta o risco de transmissão do COVID-19 por usuários contaminados, pela dispersão de partículas no ar exalado1. Entretanto, mesmo nesse cenário de maior risco de contágio, um estudo recente realizado durante o período de quarentena na França, com dados de telemonitoramento de 7.485 indivíduos com AOS, demonstrou um aumento na adesão à PAP de 3,9\%. Os autores creditaram esse aumento na adesão a três fatores: 1) por se tratar de um vírus que traz consequências para o sistema respiratório; 2) pacientes com AOS frequentemente apresentam comorbidades associadas que são fatores de risco para infecção por Covid-19; 3) o confinamento ou a redução do estresse ocupacional possam ser fatores adicionais contribuindo para maior tempo de utilização da PAP2.

Embasado nas melhores evidências científicas disponíveis, este documento objetiva esclarecer e auxiliar o fisioterapeuta a conduzir e orientar seus pacientes durante o período de pandemia da COVID-19.

\section{Questões Técnicas sobre Dispersão de Partículas pela Válvula Exalatória da Interface}

Estudos prévios incluindo indivíduos com síndrome respiratória aguda grave (SARS) em ventilação não invasiva (VNI) causada por H1N1 e tuberculose, mostraram que durante o uso de PAP a dispersão de partículas chegou a atingir cerca de um metro de distância no ambiente, podendo ser ainda maior quando em uso de pressões mais elevadas. ${ }^{3 ; 4}$ Dados recentes publicados em pacientes com 
COVID-19 sugerem que a produção e dispersão de partículas em usuários de VNI (CPAP e Binível equipamento com dois níveis de pressão positiva), variaram de acordo com os parâmetros utilizados, com o modelo e tipo de interface, podendo passar de $90 \mathrm{~cm}$ de alcance (Figura 1). ${ }^{5}$

Figura 1 | Distâncias de dispersão do aerossol $(\mathrm{cm})$ para várias modalidades de suplementação de oxigênio. A distância representada é a dispersão média na quantidade de fluxo normalmente usada para essa modalidade (cânula nasal: varia de 3 a $40 \mathrm{~cm}$; máscara simples de $\mathrm{O}_{2}$ : em todos os fluxos $\approx 30 \mathrm{~cm}$; máscara de Venturi: 33 a $40 \mathrm{~cm}$; máscaras não-ventiladas (NRM): em todos os fluxos $<10$ $\mathrm{cm}$; Sistema de oxigênio de alto fluxo (HFNO): 4,8 a $17 \mathrm{~cm}$; ventilação não-invasiva (NiPPV): 85 a $95 \mathrm{~cm}$; nebulizadores $<80 \mathrm{~cm}$ ).

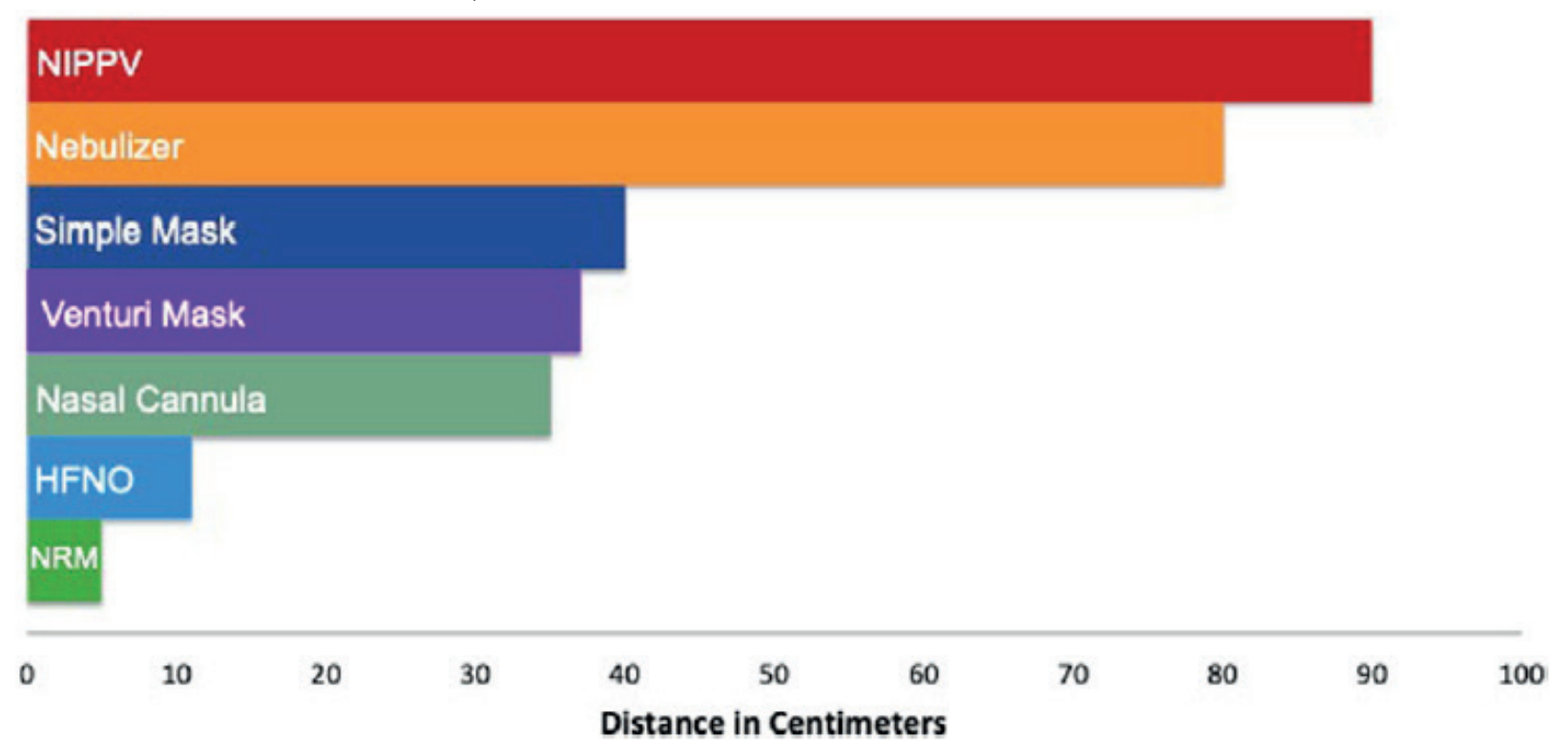

Fonte: Adaptado de Whittle JS, 2020.

Outros fatores importantes que amplificam a dispersão de partículas no ambiente se referem ao vazamento não intencional, devido a:

1. Formato, tamanho e tipo da máscara inadequados;

2. Fixação inadequada.

\section{Orientações para os Usuários de Terapia PAP para Distúrbios Respiratórios do Sono (DRS) ${ }^{6 ;} 7 ; 8 ; 9 ; 10 ; 11$}

A discussão sobre a manutenção ou não do uso do dispositivo de terapia pressórica gera opiniões controversas entre os especialistas da área. ${ }^{12 ;}{ }^{13}$ Enquanto alguns discutem que a PAP para a apneia do sono não é suporte de vida e poderia ser interrompida, outros pesquisadores alertam sobre o risco de interrupção do tratamento, principalmente relacionados à possíveis descompensações de comorbidades associadas, piora no funcionamento do sistema imunológico e, principalmente, descompensações emocionais em um momento global tão delicado (a literatura traz fortes evidências relacionando alterações de humor e sintomas depressivos em indivíduos com a apneia do sono não tratada ${ }^{14}$ ). Porém, tanto a Academia Americana do Sono (AASM - American Sleep Academy) quanto a Associação 
Brasileira do Sono (ABS) recomendam a continuidade do tratamento, seguindo as orientações que listaremos a seguir. $6 ; 11 ; 15$

\section{Uso de PAP em indivíduos sem suspeita de COVID-19:}

- Manter o uso da PAP normalmente;

- Assegurar um bom ajuste da máscara a fim de reduzir vazamentos não intencionais;

- Assegurar o uso de máscara adequada à anatomia dos contornos faciais, minimizando vazamentos;

- A higiene de rotina deve ser intensificada:

- Lavar diariamente a máscara e a traqueia com água e sabão/detergente ou, na falta destes, com álcool 70\%;

Nota: o álcool $70 \%$ pode alterar a maleabilidade dos materiais e diminuir sua vida útil. Utilize o álcool 70\% somente se for necessário.

- Limpar as superfícies do quarto com álcool 70\%;

- Manter o quarto de dormir com ventilação natural;

- $\quad$ Não compartilhar máscaras e equipamentos de PAP.

\section{Orientações adicionais do uso de PAP em caso suspeito ou confirmado de COVID-19, sem} sinais de insuficiência respiratória:

- Se um usuário de PAP apresentar sintomas sugestivos de COVID-19 é importante seguir as orientações do Ministério da Saúde ${ }^{17}$ e entrar em contato com um profissional de saúde;

- Se houver possibilidade de isolamento do paciente num outro cômodo, o tratamento com a PAP durante esse período poderá ter continuidade, principalmente se a síndrome gripal não estiver associada a produção de secreção. Nesse cenário, é necessária a higiene diária de todo o ambiente durante todo o período de isolamento;

- Se possível, fechar a porta do quarto e dormir com janelas abertas. A abertura das janelas diminui em até $63 \%$ a concentração viral no ambiente. ${ }^{12} \mathrm{O}$ uso de ar condicionado do tipo Split, com portas e janelas fechadas não é recomendado, pois não existe renovação do ar e o fluxo de ar turbilhonado mantém as partículas aerossolizadas em suspensão;

- Caso não seja possível o isolamento num cômodo separado do domicílio, o fisioterapeuta ou outro profissional de saúde deve estar atento, pois o uso da PAP pode aumentar o risco do contágio aos demais residentes. Nessa condição, torna-se ainda mais importante a discussão multiprofissional sobre a condição clínica do usuário de PAP e da possibilidade de suspensão temporária deste tratamento;

- Importante considerar que a presença de secreção - síndrome "gripal úmida" - em pacientes em uso de PAP irá promover maior dispersão de partículas e maior risco de contágio, reforçando a necessidade de discussão multiprofissional para avaliar a condição clínica do paciente e a possibilidade de suspensão temporária do tratamento com PAP. 


\section{Advertência sobre o uso de dispositivos de terapia PAP para DRS na insuficiência respiratória}

Recentemente o FDA (U.S. Food and Drug Administration)18 publicou uma diretriz online viabilizando o uso de dispositivos de pressão positiva contínua nas vias aéreas (CPAP), auto-CPAP e Binível - normalmente usadas para o tratamento da apneia do sono - para dar suporte a pacientes com insuficiência respiratória. Entretanto, trata-se de uma recomendação aceita apenas em casos estritos de falta de ventiladores mecânicos apropriados para a demanda vigente de pacientes. Este uso está restrito ao ambiente hospitalar com instalações e equipamentos adequados (p. ex., sala com pressão negativa, aparelho com ramo inspiratório e expiratório, uso de filtro HEPA no ramo expiratório etc.), e sob supervisão de equipe especializada.

Esta exceção não libera o tratamento de insuficiência respiratória por Covid19 com esses dispositivos pressóricos no ambiente familiar. Na vigência de sinais e sintomas de desconforto respiratório, o paciente deverá ser orientado a procurar imediatamente atendimento médico-hospitalar.

\section{Orientações sobre o Atendimento de Pacientes com DRS}

Durante o período de pandemia, pacientes que tenham sido previamente atendidos devem ser acompanhados, preferencialmente, por teleconsulta, teleconsultoria e telemonitoramento (Resolução $\mathrm{n}^{\circ} 516$ aprovada pelo COFFITO, em caráter de excepcionalidade, publicada no Diário Oficial da União no dia 23 de março de 2020). ${ }^{19}$

Recomenda-se, sempre que possível, a suspensão de novos atendimentos neste momento de pandemia. ${ }^{6 ; 11 ; 15}$ Nas situações em que houver necessidade de consultas presenciais ou de atendimento de um novo paciente em caráter de urgência, o atendimento poderá ser realizado no domicílio ou em consultório, desde que sejam garantidos todos os cuidados para prevenir a contaminação, conforme recomendações a seguir:

- Atendimento presencial em domicílio ou consultório:

- Usar equipamentos de proteção individual - EPI (vide sessão a seguir).

- Atendimento em consultório:

- Limpar frequentemente as instalações do consultório (incluindo qualquer lugar de manuseio corriqueiro como maçanetas, descargas, misturadores, interruptores, bancadas de apoio, teclado, mouse do computador e botões liga/desliga dos equipamentos);

- Higienizar com spray de álcool 70\% a mesa e as demais superfícies de contato;

- Instalar avisos - em lugar visível - sobre "etiqueta da tosse";

- Disponibilizar em locais estratégicos álcool 70\% em gel para higienização das mãos;

- Agendar os atendimentos com um amplo espaçamento de tempo entre uma consulta e outra, para evitar aglomeração de pacientes na clínica.

- Sugerir que o paciente vá só ou com apenas 01 acompanhante à consulta

- Atendimento domiciliar:

- Higienizar com spray de álcool 70\% qualquer material manuseado pelo fisioterapeuta, incluindo bolsa pessoal e telefone celular/smartphone/tablet, tanto na entrada como na saída da residência. 
Antes de confirmar o atendimento presencial, o fisioterapeuta deverá questionar ao paciente e acompanhante (se sua presença for imprescindível) sobre qualquer sintoma de "virose respiratória". Considerando que eticamente não podemos nos recusar ao atendimento, sugerimos ampliar os cuidados de proteção individual (vide sessão de EPIs), manter distância mínima de 1,5 m, sempre que possível, e, se necessário, encaminhar o paciente para um serviço de saúde. $\mathrm{O}$ fisioterapeuta não deve realizar atendimento quando apresentar qualquer sinal de "virose respiratória".

O teste de ajuste de máscaras, assim como o empréstimo dessas interfaces e/ou traqueias devem ser feitos mediante medidas de desinfecção de alto nível (uso de Ortoftalaldehído 0,55\% ou Ácido Peracético $0,15 \%$ ou Glutaraldehído $3,4 \%$ ou $2 \%$ - encontrados usualmente em farmácias) ${ }^{15}$ ou de acordo com as orientações de desinfecção/esterilização do guia multiusuários de cada fabricante das interfaces e materiais utilizados. Caso contrário, sugerimos usar produtos lacrados (novos) para a adaptação.

No caso de uso da solução 0,55\% de Ortoftalaldehído (solução Cidex OPA 0,55\%);

- Mergulhar a máscara ou o tubo no Ortoftalaldehído a 0,55\% e mantenha-o submerso por 12 minutos;

- Enxágue com água em abundância;

- Seque sem expor à luz solar direta;

- Conserve em um recipiente limpo e desinfectado, capaz de preservar a desinfecção.

No caso de uso do Ácido Peracético 0,15\%:

- Mergulhar a máscara ou o tubo em 0,15\% de Ácido Peracético e mantenha-o submerso por 10 minutos;

- Enxágue com água em abundância;

- Seque sem expor à luz solar direta;

- Conserve em um recipiente limpo e desinfectado.

No caso de uso do Glutaraldehído 3,4\% ou 2\%:

- Mantenha as peças imersas por 20 minutos a $3,4 \%$ ou 45 minutos se a $2 \%$;

- Enxágue com água em abundância;

- Seque sem expor à luz solar direta;

- Conserve em um recipiente limpo e desinfectado.

Estudos recentes demostraram uma sobrevida longa do vírus em materiais plásticos e metais, confirmando a viabilidade viral em até $72 \mathrm{~h} .{ }^{20}$ Tanto para o caso de teste com interfaces como para locação de dispositivos pressóricos, recomendamos que após a coleta os materiais utilizados sejam mantidos em uma embalagem plástica fechada por até três dias, quando então poderão ser manuseados para higienização e desinfecção. ${ }^{21}$ Sugerimos manter os dispositivos PAP em um período de "quarentena" (pelo menos uma semana) antes de sua realocação, mesmo após higienização adequada. ${ }^{16}$

Como medida complementar de precaução, sugere-se o uso do filtro bacteriológico (filtro $\mathrm{AB}$ ) acoplado na saída de ar do equipamento, entre o aparelho e a traqueia (Figura 2). ${ }^{5}$ Ao adicionar o filtro $\mathrm{AB}$ deve-se obrigatoriamente considerar um aumento do espaço morto e da resistência no sistema de 2,2 até $4 \mathrm{cmH}_{2} \mathrm{O} / \mathrm{L} / \mathrm{s}$, variando de acordo com o material, o tempo de utilização e as características hidrofóbicas do material. ${ }^{22 ;}$ 23; 24 Alguns equipamentos de PAP possuem em seu menu clínico a possibilidade de autoajuste para o aumento da resistência causada pela adição do filtro AB. Para aqueles equipamentos que não possuem o autoajuste, considere a possibilidade de adequação da pressão 
terapêutica para manter sua efetividade. Adicionalmente, recomendamos a desativação do sistema de umidificação enquanto o filtro bacteriológico estiver sendo utilizado para que não ocorra perda da eficácia do filtro. ${ }^{25 ; 26} \mathrm{~A}$ periodicidade de troca do filtro $\mathrm{AB}$ deverá seguir as orientações do fabricante.

Figura 2 Exemplo de posicionamento do filtro bacteriológico entre o dispositivo de pressão positiva e a traqueia do equipamento (A: imagem da parte lateral do aparelho; B: imagem da parte traseira do aparelho).
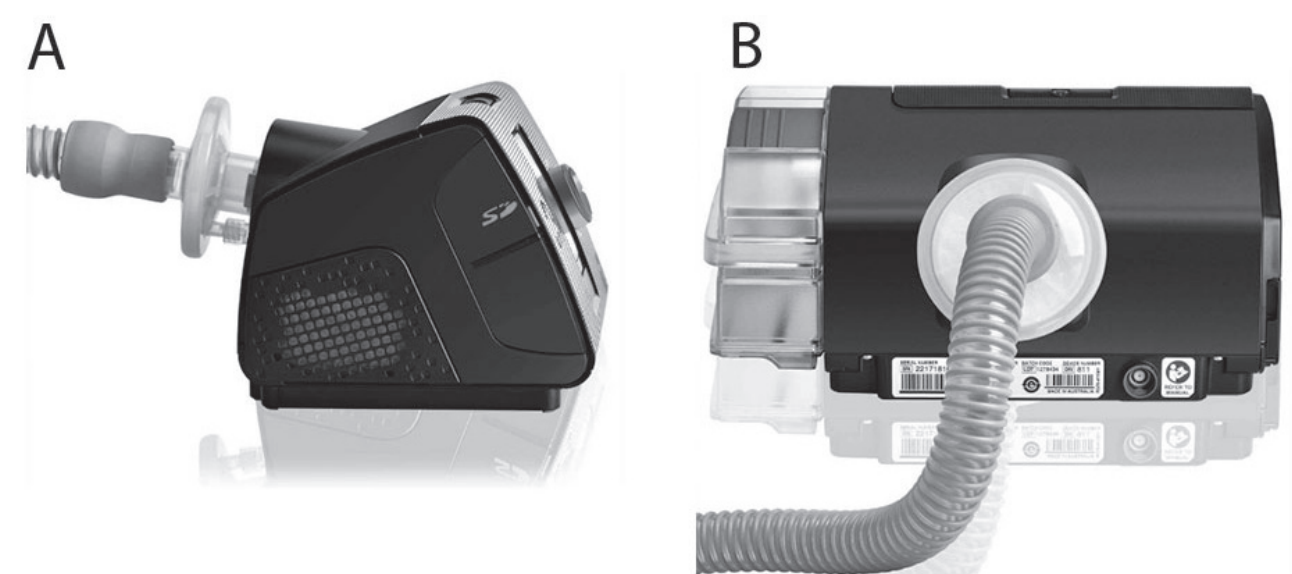

Fonte: https://www.weathersavvy.com/products/universal-bacterial-viral-filter-for-cpapbipap-machine-filters?variant=31743264751652.

É importante mencionar que até o momento da elaboração deste documento, os estudos científicos apresentados estão relacionados ao uso de filtros bacteriológicos em equipamentos de pressão positiva no ambiente hospitalar e, em grande maioria, com sistema fechado de ventilação. Não foram encontradas na literatura referências sobre o uso de filtros $\mathrm{AB}$ em equipamentos para o tratamento de apneia do sono no ambiente domiciliar.

Também não foram encontrados dados na literatura que sugerissem a suspensão do uso do sistema de umidificação, em função da pandemia Covid-19, para aqueles usuários de terapia PAP em tratamento de distúrbios respiratórios do sono e que possuem equipamento próprio (de uso exclusivo).

Portanto, a adição do filtro $\mathrm{AB}$ para multiusuários e o desligamento do sistema de umidificação para usuário único devem ficar a critério do profissional.

Adicionalmente, dispositivos de higienização que utilizam ozônio ou luz ultravioleta (UV) para limpar os equipamentos PAP e acessórios podem ser utilizados para sistemas multiusuários, mas não são necessariamente superiores aos métodos de limpeza e cuidados descritos acima. Para o uso adequado destes dispositivos de higienização é muito importante seguir cuidadosamente as instruções do fabricante. ${ }^{27}$ Não existe recomendação na literatura para o uso destes sistemas de higienização em usuário único.

\section{Equipamentos de proteção individual (EPI) ${ }^{6 ; 11}$}

Os EPIs sugeridos para o atendimento domiciliar ou em consultório são: touca, luvas, avental descartável, óculos e protetor facial filtrante (PFF2 ou N95). Deve-se usar calça comprida e calçados fechados, de modo a evitar a exposição da pele.

Não há dados que assegurem a efetividade da reutilização do respirador N95 com sobreposição 
da máscara cirúrgica (que poderia ser substituída mais frequentemente). Entretanto, essa prática tem sido adotada devido ao alto custo do material e escassez de EPIs.

Para colocação dos EPIs, observar a seguinte sequência:

- Higienizar as mãos e materiais a serem utilizados;

- Paramentação com avental, touca, óculos;

- Nova higienização das mãos;

- Colocação do respirador N95;

- Colocação sobreposta da máscara cirúrgica;

- Colocação de dois pares de luvas.

Ao finalizar o atendimento, deve-se:

- Retirar lentamente e em sequência: avental e touca;

- Retirar um par de luvas e, em seguida, os óculos - já podendo higienizá-lo juntamente com demais itens como oxímetro de pulso, estetoscópio etc.;

- Retirar a máscara cirúrgica;

- Retirar o segundo par de luvas;

- Higienizar as mãos;

- Retirar o respirador N95;

- Devido à escassez, tem sido aceita a utilização do N95 por mais vezes, desde que não haja sujidade.

Pacientes sintomáticos ou com confirmação de COVID-19 devem usar máscara cirúrgica, se disponível, ou máscara caseira. No caso de pacientes assintomáticos, o uso de máscara caseira tem sido recomendado. Com exceção dos óculos de proteção, que deverão ser higienizados com álcool $70 \%$, e do respirador N95, que pode ser reutilizado, os demais EPIs devem ser imediatamente descartados após o atendimento, principalmente pelo risco de contaminação cruzada.

Lembramos que a paramentação adequada do fisioterapeuta deve ser realizada antes do atendimento e que deve haver especial atenção ao descarte dos EPIs, principalmente no atendimento domiciliar. Leve consigo sacos plásticos para armazenamento do material utilizado e posterior descarte adequado.

\section{Considerações Finais}

No atual cenário dinâmico de pandemia COVID-19 o fisioterapeuta deve estar atualizado sobre o manejo adequado dos equipamentos e acessórios para o tratamento da apneia do sono, sobre as orientações e recomendações que devem ser feitas ao paciente, e estratégias para o atendimento individualizado. Reforçamos que os profissionais devem utilizar todos os EPIs para sua segurança, dos pacientes e das demais pessoas em seu entorno. A instituição desses procedimentos contribuirá para o maior nível de segurança na assistência fisioterápica.

\section{Referências}

1. Guan L, Zhou L, Zhang J, Peng W, Chen R. More awareness is needed for severe acute respiratory syndrome coronavirus 2019 transmission through exhaled air during non-invasive respiratory support: experience from China. Eur Respir J. 2020 Mar 20;55(3):2000352. doi: 10.1183/13993003.00352-2020. 
2. Attias D, Pepin JL, Pathak A. Impact of COVID-19 lockdown on adherence to continuous positive airway pressure (CPAP) by obstructive sleep apnoea patients. Eur Respir J. 2020 Jul 30;56(1):2001607. doi: 10.1183/13993003.01607-2020.

3. Hui DS, Chow BK, Ng SS, Chu LCY, Hall SD, Gin T, et al. Exhaled air dispersion distances during noninvasive ventilation via different Respironics face masks. Chest. 2009 Oct;136(4):998-1005. doi: 10.1378/chest.09-0434. Epub 2009 May 1.

4. Esquinas AM, Egbert Pravinkumar S, Scala R, Gay P, Soroksky A, Girault C, et al. Noninvasive mechanical ventilation in high-risk pulmonary infections: a clinical review. Eur Respir Rev. 2014 Dec;23(134):427-38. doi: 10.1183/09059180.00009413.

5. Whittle JS, Pavlov I, Sacchetti AD, Atwood C, Rosenberg MS. Respiratory support for adult patients with COVID-19. J Am Coll Emerg Physicians Open. 2020 Apr 13;10.1002/emp2.12071. doi: 10.1002/ emp2.12071. Online ahead of print.

6. ABS. Segundo boletim Covid [Internet]. São Paulo: Associação Brasileira do Sono; 2020. Available from: https://www.absono.com.br/assets/2covid boletim abs.pdf.

7. Government, UK. Coronavirus (COVID-19): UK government response [Internet]. London; 2020. Available from: https://www.gov.uk/government/topical-events/coronavirus-covid-19-uk-governmentresponse.

8. CHEST. COVID-19: Updates and Resources [Internet]. Glenview: American College of Chest Physicians; 2020. Available from: https://www.chestnet.org/Guidelines-and-Resources/COVID-19/ Updates-and-Resources\#PracticeManagementResources.

9. ABS. Orientações para o uso do CPAP / BiPAP e recomendações para a sua higienização [Internet]. São Paulo: Associação Brasileira do Sono; 2020. Available from: https://www.absono.com.br/assets/higien cpap.pdf.

10. Craig S, West S, OSA Alliance. Guidance regarding coronavirus (COVID-19) and Obstructive Sleep Apnoea (OSA): for people who routinely use continuous positive airway pressure (CPAP), their families and health care workers [Internet]. [place unknown: OSA Alliance]; 2020 Mar 20. Available from: https://www.brit-thoracic.org.uk/media/455098/osa-alliance-cpap-covid-19-advice-20-3-20-v10.pdf.

11. AASM. COVID-19: FAQs for Sleep Clinicians [Internet]. Darien: American Academy of Sleep Medicine; 2020. Available from: https://aasm.org/covid-19-resources/covid-19-faq/.

12. Baker JG, Sovani M. Case for continuing community NIV and CPAP during the COVID-19 epidemic. Thorax. 2020 May;75(5):368. doi: 10.1136/thoraxjnl-2020-214913. Epub 2020 Apr 9.

13. Barker J, Oyefeso O, Koeckerling D, Mudalige NL, Pan D. COVID-19: community CPAP and NIV should be stopped unless medically necessary to support life. Thorax. 2020 May;75(5):367. doi: 10.1136/thoraxjnl-2020-214890. Epub 2020 Apr 9.

14. Patil SP, Ayappa IA, Caples SM, Kimoff RJ, Patel SR, Harrod CG. Treatment of Adult Obstructive Sleep Apnea With Positive Airway Pressure: An American Academy of Sleep Medicine Systematic Review, Meta-Analysis, and GRADE Assessment. J Clin Sleep Med. 2019 Feb 15;15(2):301-334. doi: $10.5664 / \mathrm{jcsm} .7638$.

15. ABS. Quinto boletim Covid [Internet]. São Paulo: Associação Brasileira do Sono; 2020. Available from: https://www.absono.com.br/assets/5boletim covid19.pdf. 
16. Kampf G, Todt D, Pfaender S, Steinmann E. Persistence of coronaviruses on inanimate surfaces and their inactivation with biocidal agents. J Hosp Infect. 2020 Mar;104(3):246-251. doi: 10.1016/j. jhin.2020.01.022. Epub 2020 Feb 6.

17. Brasil. Ministério da Saúde. Coronavírus: o que você precisa saber [Internet]. Brasília: Ministério da Saúde; 2020. Available from: https://coronavirus.saude.gov.br/.

18. FDA. Ventilator Supply Mitigation Strategies: Letter to Health Care Providers [Internet]. Silver Spring: Food and Drug Administration; [2020 Mar 22]. Available from: https://www.fda.gov/medical-devices/ letters-health-care-providers/ventilator-supply-mitigation-strategies-letter-health-care-providers.

19. COFFITO. Resolução no 516, de 20 de março de 2020. Dispõe sobre a suspensão temporária do Artigo 15, inciso II e Artigo 39 da Resolução COFFITO no 424/2013 e Artigo 15, inciso II e Artigo 39 da Resolução COFFITO n ${ }^{\circ}$ 425/2013 e estabelece outras providências durante o enfrentamento da crise provocada pela Pandemia do COVID-19 [Internet]. Brasília: Conselho Federal de Fisioterapia e Terapia Ocupacional; 2020. Available from: https:/www.coffito.gov.br/nsite/wp-content/uploads/2020/03/ Resolucao516 2020.pdf.

20. van Doremalen N, Bushmaker T, Morris DH, Holbrook MG, Gamble A, Williamson BN, et al. Aerosol and Surface Stability of SARS-CoV-2 as Compared with SARS-CoV-1. N Engl J Med. 2020 Apr 16;382(16):1564-1567. doi: 10.1056/NEJMc2004973. Epub 2020 Mar 17.

21. Bastier P-L, Aisenberg N, Durand F, Lestang P, Abedipour D, Gallet de Santerre O, et al. Treatment of sleep apnea by ENT specialists during the COVID-19 pandemic. Eur Ann Otorhinolaryngol Head Neck Dis. 2020 May 11;S1879-7296(20)30120-4. doi: 10.1016/j.anorl.2020.05.001. Online ahead of print.

22. Buckley PM. Increase in resistance of in-line breathing filters in humidified air. Br J Anaesth. 1984 Jun;56(6):637-43. doi: 10.1093/bja/56.6.637.

23. Gazola NLG; Machado FO, Lima WC, Silva HP, Gulini JEHMB. [Evaluation of resistance imposed by heat exchangers and moisture filters of airway in patients with mechanical ventilatory support]. Fisioter. Bras. 2011 Sept-Oct;12(5):353-358. Portuguese.

24. Wilkes AR. Heat and moisture exchangers and breathing system filters: their use in anaesthesia and intensive care. Part 2 - practical use, including problems, and their use with paediatric patients. Anaesthesia. 2011 Jan;66(1):40-51. doi: 10.1111/j.1365-2044.2010.06564.x. Epub 2010 Nov 30.

25. Turnbull D, Fisher PC, Mills GH, Morgan-Hughes NJ. Performance of breathing filters under wet conditions: a laboratory evaluation.Br J Anaesth. 2005 May;94(5):675-82. doi: 10.1093/bja/aei091. Epub 2005 Feb 25.

26. Wilkes AR. Heat and moisture exchangers and breathing system filters: their use in anaesthesia and intensive care. Part 1 - history, principles and efficiency. Anaesthesia. 2011 Jan;66(1):31-9. doi: 10.1111/j.1365-2044.2010.06563.x. Epub 2010 Nov 25.

27. Schotland H. The Care and Cleaning of your PAP Device. Am J Respir Crit Care Med. 2020 Jun 1;201(11):P23-P24. doi: 10.1164/rccm.2020C3.

Submissão em: 08/06/2020

Aceite em: 15/07/2020 